\title{
2213. Improvement of the durability of rolling bearings in high-speed drive systems
}

\author{
Piotr Deuszkiewicz \\ Institute of Machine Design Fundamentals, Faculty of Automotive and Construction Machinery \\ Engineering, Warsaw University of Technology, Warsaw, Poland \\ E-mail: uszy@simr.pw.edu.pl
}

Received 16 January 2016; received in revised form 3 October 2016; accepted 20 October 2016

DOI https://doi.org/10.21595/jve.2016.17861

\begin{abstract}
At present, in many high-speed machines (e.g. appliances) bearing systems based on ball bearings. These solutions are used because of the low cost of production. However, in the process of operation, it appears that the use of this type of bearings has low durability of the system associated with its underload. In these systems, the output shaft rotates at a very high speed (20 thousand RPM), so even slight imbalance causes very high inertia forces aggravating bearings with dynamic reactions. These reactions rotate with the shaft, and their rotation frequency is equal to the frequency of the shaft rotation. Clearances in the bearing lead to the situation where the shaft together with the inner ring vibrates. These vibrations cause the slip between the balls and the cage of the bearing. As a result, the cage is a subject to accelerated damage because of sliding and collisions with the balls. Another factor affecting the durability of the bearing system is work at temperatures exceeding permissible limits. The article compares two design solutions and their impact on the life of the bearings used. In the original construction very fast wear of bearings takes place, and thus the damage of the whole device. In a second experiment there was examined the durability of the system with the use of tension of the bearings with axial spring. The initial effects of changes in structure of the system have led to a change of bearing lubrication. The final result of the re-search was a proposal to change such a structure eliminating the problem of accelerated wear of the bearings.
\end{abstract}

Keywords: vibration symptom, durability of rolling bearings, high speed drive systems, right condition of lubrication, initial tension.

\section{Introduction}

Reviewing recent publications on rolling bearings I consider that one problem is still unsolved despite the research on rolling bearings is one of the best documented areas of machine design. There are a lot of works dealing with the damage and diagnostics bearings operating under harsh environmental conditions [1], an overload condition or bearings made of unusual materials [2]. Much space is devoted to modeling the phenomena occurring in the bearing during operation [3-5] and learning mechanisms that cause development of defects [6-10]. Other authors focus rather on the detection and classification than getting to know the causes of the various types of bearing damages [11-13]. And the last group of researchers are Authors that are dealing with diagnosis and on-line condition monitoring [14-16]. But I don't find any work about the problem of durability such bearings working in the state of underload. The only one thing I found was recommendation in the FAG catalog, that the minimum load value for ball bearings should be greater than 0.01 of nominal load. There are no published results of works on the use of conventional ball bearings in high-speed systems such as drives of headstocks, household appliances, etc. These solutions are used because of the low cost of production, however, it turns out that they are characterized by low durability of the system related to bearings underload. Different manufacturers deal with this problem in different ways. For example, they use glues for retention of the bearings in the housing or spring washers whose purpose is to load the bearings and get rid of clearances which are present in those bearings, which leads to increasing the durability of the system. But there is no scientific explanation of this problem, so in specific applications, it turns out that the current state of knowledge is insufficient and needs to be 
expanded.

The paper attempts to answer how to increase bearings life by initial tension and thereby reduce the level of vibrations.

\section{Experiment genesis and preparation}

The device used for refreshing the air in industrial halls was used for the research. In this position (Fig. 1) ball bearings 6001-2Z (2Z indicates double-sided sealed bearings) with of standard quality were used in the bearing system. Experiment was conducted in anechoic chamber due to very high level of generated noise (in order to attach accelerometers directly over the bearings we had to remove the soundproof covers).

In constructional solution (Fig. 2) there were used two bearings mounted rigidly on the shaft. The location in the housing is a floating type and allows to move the system of rotor axially by about $1 \mathrm{~mm}$. At the free end of the shaft, doubled fan pushing the air through system of the nozzles. At the other end of the shaft, the pulley driven by the belt is placed. During the device operation by the user, it turned out that the bearing on the fan side is worn faster (i.e. after 50-60 hours) and, in extreme cases the cage is completely damaged, which leads to the damage of the rotor shaft. After checking the loads, there appeared some assumptions that low durability may be caused by the underload of the system. This situation results in a low axial stiffness and thus in increased level of vibrations in the bearing nodes, which in turn entails accelerated wear of the rolling elements and the failure of the drive system.

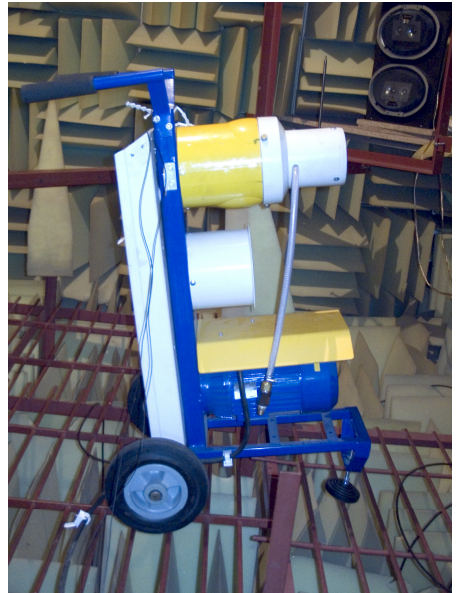

Fig. 1. Industrial air freshener

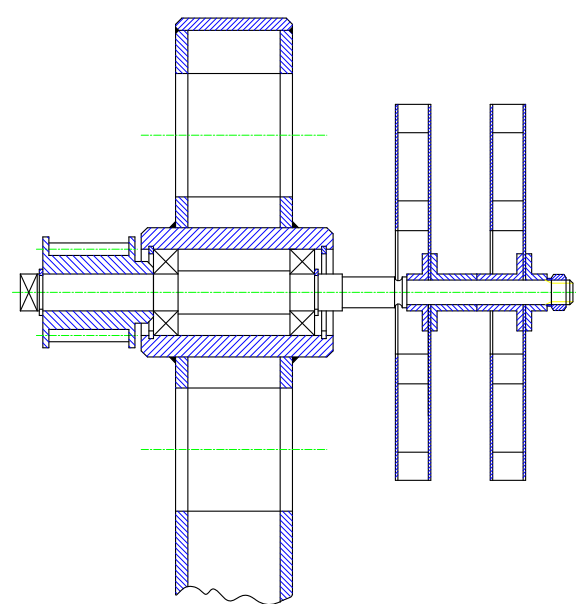

Fig. 2. Diagram of bearing of the examined object

In the investigated system, the output shaft rotates at very high rotational speed (over $19,000 \mathrm{rpm}$ ), that is why even a slight imbalance causes large inertia forces loading the bearings with dynamic reactions. These reactions rotate with the shaft, and their rotation frequency is equal to the frequency of the shaft rotation. Clearances in the bearing lead to the situation where the shaft together with the inner ring vibrates. These vibrations cause the slip between the balls and the cage of the bearing and as a consequence of this the balls hits on the rings and the cage, which in turn causes the formation of cavities on the surface of the ring. Due to the interaction of balls with the ring, the cavities grow and cause additional vibrations in the bearing. The cage may be destroyed due to the slip and collisions with the balls.

If the load of the bearing is too small, and the rotational speed is high there may appear the slip, which with insufficient lubrication can lead to bearing damage. According to the FAG catalog, the minimum load value for ball bearings should be greater than 0.01 of nominal load. This ratio does not exceed 0,007 in the tested system. Therefore, it should be assumed that with 
the use of simple ball bearings 6001-2Z, the slips caused by too small load increase the load of grease, which leads to damage of cooperating surfaces due to blurring or micropitting phenomenon.

In order to answer these questions, the following experiments were done:

1) There was examined the stability of the system with the use of original solution in the form of two bearings $6001-2 Z$,

2) Another part of the experiment was to determine the spectral structure of vibrations generated by the machine during operation.

3) At the final stage of the experiment there was carried out the test of durability of bearings $6001-2 \mathrm{Z}$ with additional axial load with the strength of $100 \mathrm{~N}$ implemented with the helical spring inserted between the bearings.

In order to systematize the results of measurements there was performed an analysis of the following indicators: Peak value, RMS, Crest factor, Kurtosis, Impulse factor, Shape factor, Crest factor, Clearance factor and three mixed indicators proposed in [1-3]:

$-X S K[1-3]$ :

$X S K=\log \left(\frac{\text { Peak }}{R M S_{0} \cdot \text { Kurtosis }}+\right.$ ImpulseFactor $)$.

$-\operatorname{SecF}[1-3]$ :

SecF $=\log \left(\frac{\text { Peak }}{R M S_{0} \cdot \text { Kurtosis }}\right)+$ ImpulseFactor .

- Rice frequency $-R a[3]$ :

$R a=\sqrt{\frac{\sum_{f=1}^{f=N} A_{P W R}(f) f^{2}}{\sum_{f=1}^{f=N} A_{P W R}(f)}}$,

where: the vector of input data is acceleration time signal, $R M S_{0}$ - is a reference value of the indicator $R M S$ (typically for a brand new bearing), $A_{P W R}$ - is the power amplitude spectrum component.

We decided to use $R M S_{0}$ as a reference value because RMS is directly proportional to the energy of the phenomenon. Rice frequency give us information about the average frequency at which is distributed energy. It is a very good indicator to diagnose rotary machines [3].

\section{The test of durability of bearings 6001 mounted in the original variant.}

The measurements were carried out at the bench shown in Figure 1 in an anechoic chamber with the use of miniature accelerometers B \& K 4500 B \& K and 4501 mounted directly on the bearing node. Measurements were performed in two directions: radial and axial on the bearing housing on the fan side. Recordings of vibroacoustic signal were made by the RoadRunner's LMS

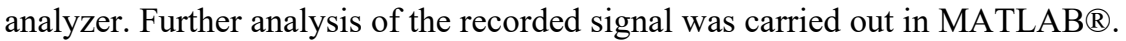

Figs. 3-4 show exemplary spectra of vibration in lateral and axial directions. After preliminary analysis it was possible to observe that the propagation of vibration energy is significantly higher in axial direction. There was clearly highlighted the impact of the solution on the level of vibrations generated in the system and the dominant influence of errors of making and installing the bearings and rotor unbalance on the spectrum of generated frequencies [4]. In addition, the supposition of the existence of bearings underload in the tested device was confirmed. The experiment was made for bearings "brand new" without their prior running in. 
After these preliminary analyses the experiment was continued in work cycles provided by the manufacturer, i.e. the station was working about eight hours a day for eight days. Measurements were carried out in three cycles, every 5 hours and at the end of each working day up to 99 hours of work. The experiment was stopped because of the clear signs of damage to the bearings and the possibility of damage to the test stand.

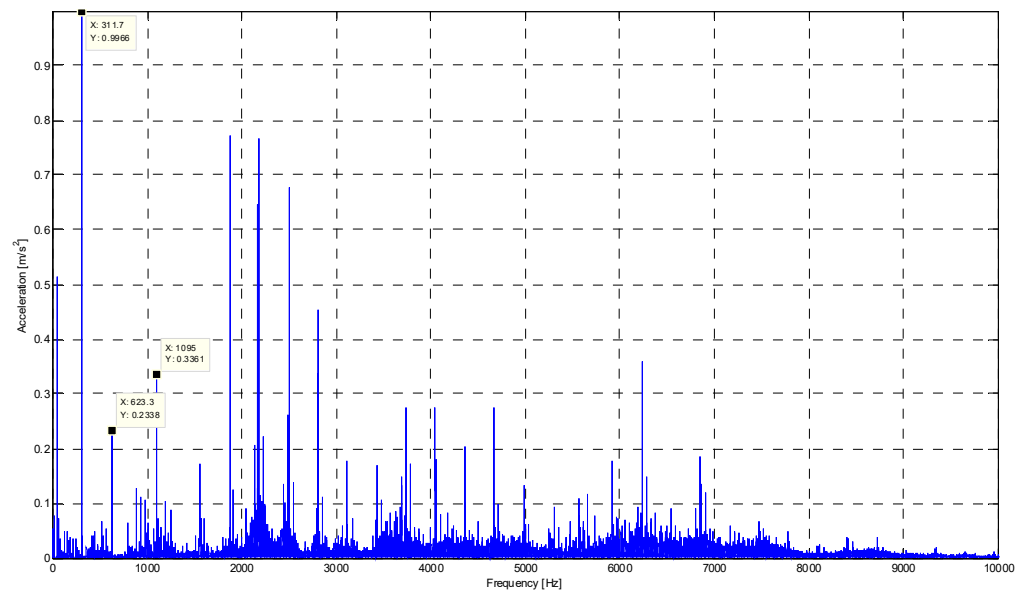

Fig. 3. Example spectrum of vibrations - the lateral direction

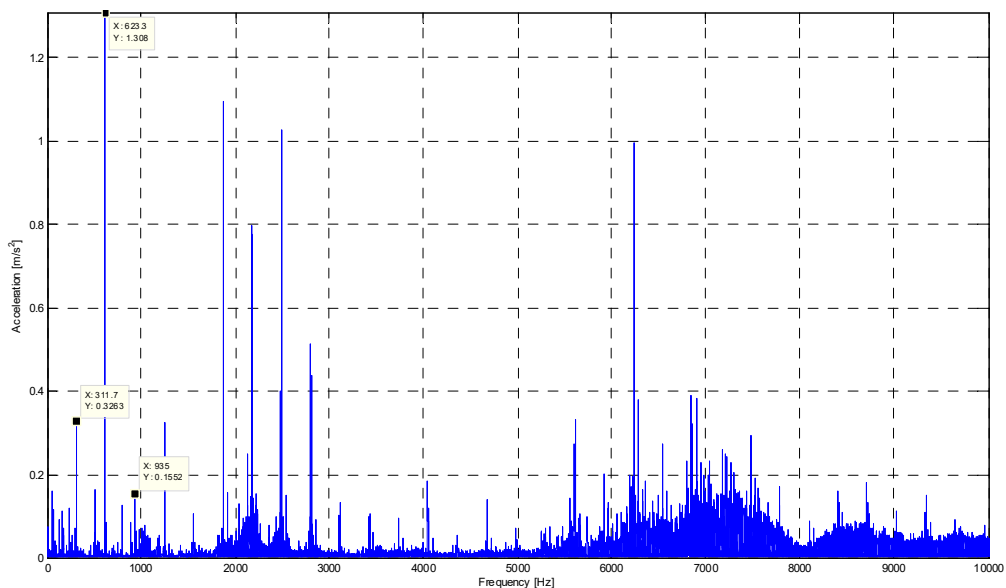

Fig. 4. Example spectrum of vibrations - axial direction

After an initial analysis of indicators, the following conclusions were formulated:

- Most indicators have a very large spread of values and it is difficult to formulate physically interpretable conclusions. In other words, it is hard to detect the initial moment of damage to the bearing on their basis. Some of them (e.g. Rice_a) are insensitive for changes of bearings state.

- At the final stage of the experiment between 55th and 99th hour of work, the selected indicators are characterized with a high randomness and therefore cease to be useful as a symptom of damage.

- Only the analysis of RMS indicator gave interpretable results, so I use it for further analysis and on its basis the following conclusions were drawn:

- Damage to the bearing is visible after 15 hours of operation,

- To achieve the 30 hours of work there can be seen an increase in vibration level with the evolution of damage. However, after that time the vibration level begins to decline, so we can suppose that the bearing is running in. 
The large dispersion of values may also result from the applied cycle of work. After every 5 hours of operation, the device was off and running after a few or several hours of the break. Such cycle of the experiment was established to simulate the real operating conditions.

Example values of Peak, RMS, XSK and Rice_a indicators are shown in Figs. 5-10.

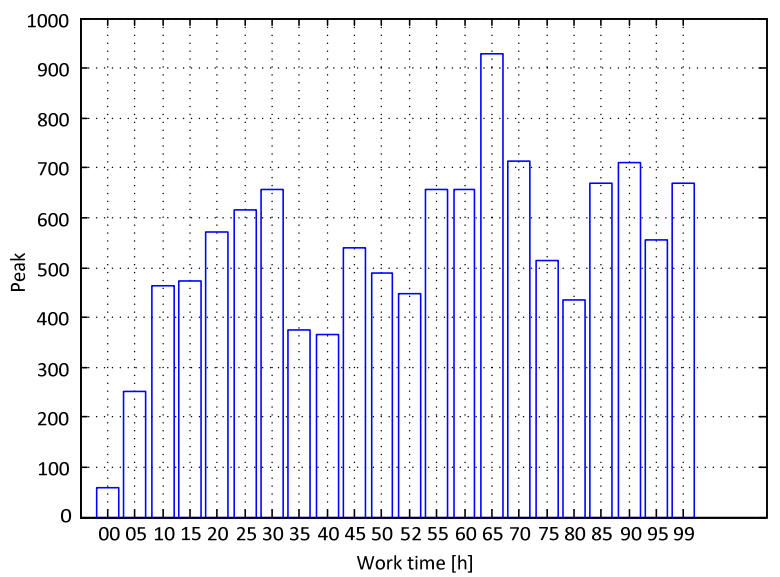

Fig. 5. Example of peak indicator - lateral vibrations

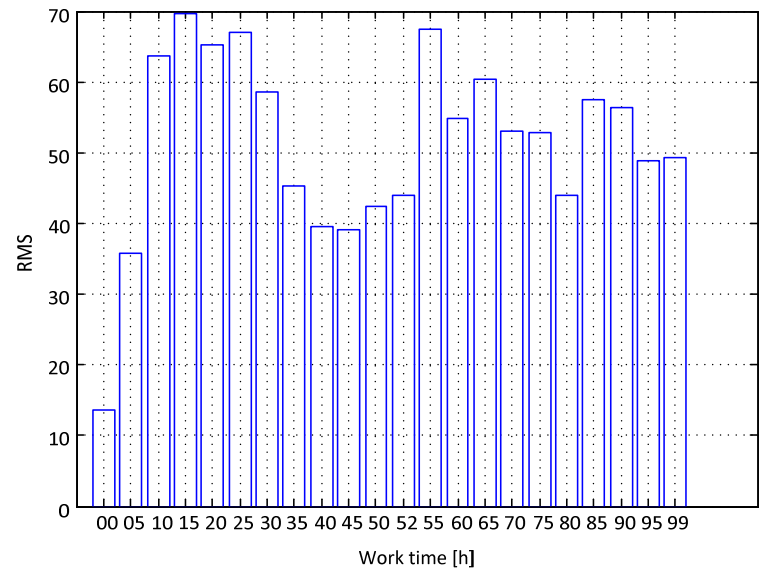

Fig. 6. Example of RMS indicator - lateral vibrations

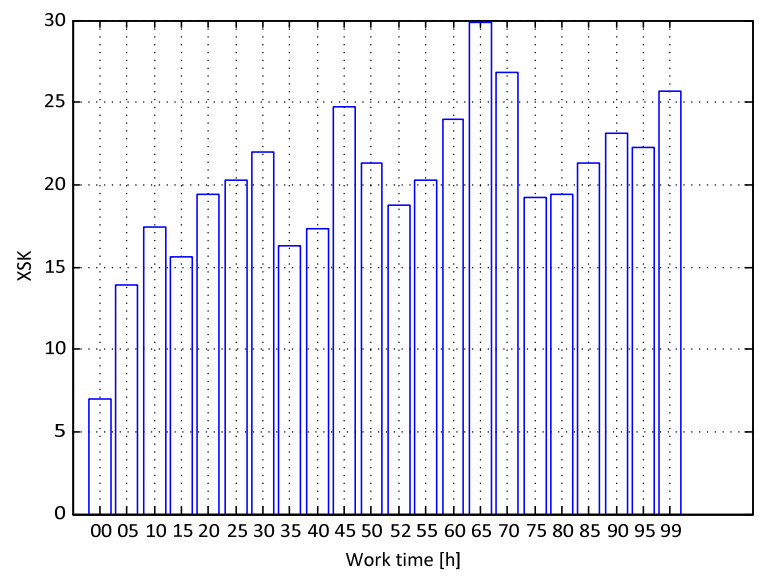

Fig. 7. Example of XSK indicator - lateral vibrations 


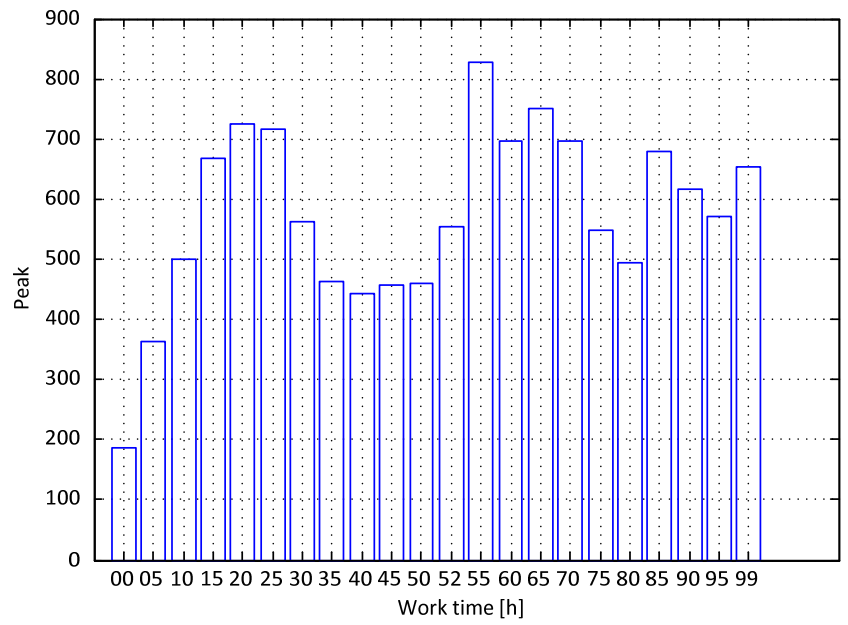

Fig. 8. Example of peak indicator - axial vibrations

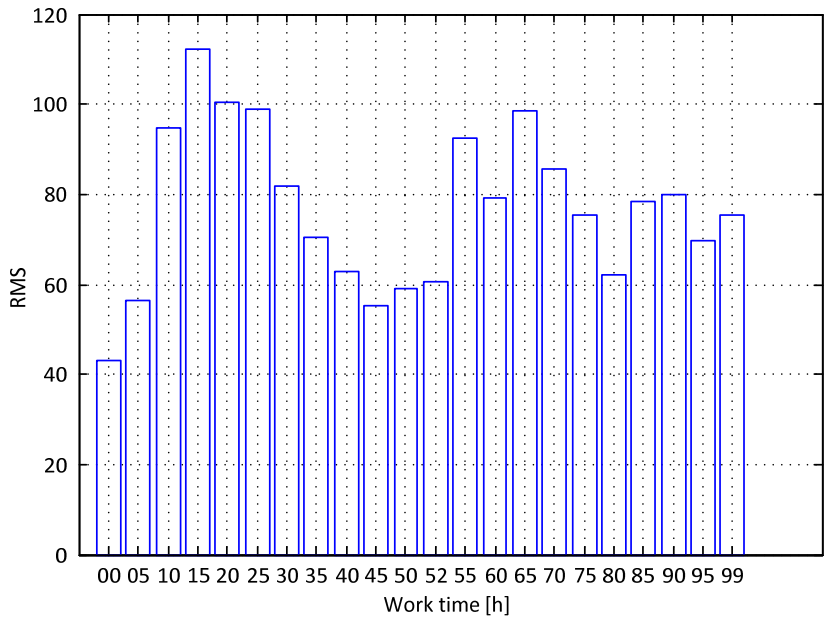

Fig. 9. Example of RMS indicator - axial vibrations

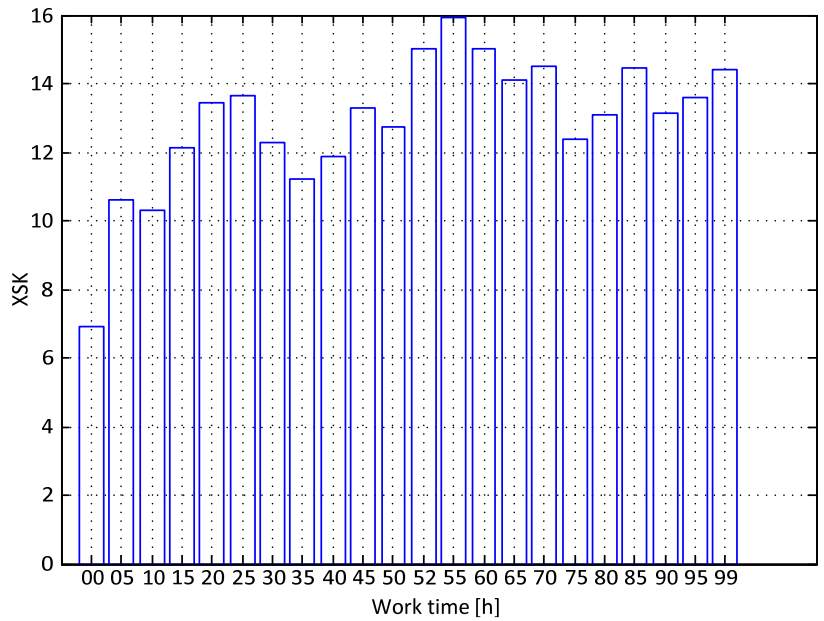

Fig. 10. Example of XSK indicator - axial vibrations 


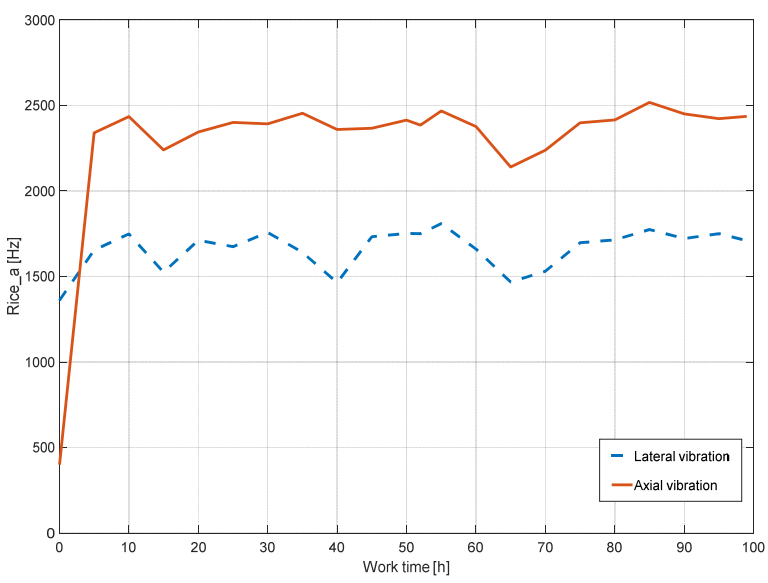

Fig. 11. Example of XSK indicator

After stopping the experiment at 99 hours of work and disassembly of the test station, the bearings were analyzed. It shows that the bearing on the fun side has a highly damaged cage and is almost completely void of grease and its remains were solidified. As a result, after rapid increase of rolling resistance, the inner and outer ring and rolling elements (balls) were damaged. This is shown in Fig. 12 where the ring damage and the change of bearing color is clearly seen. It suggests work in conditions of severe overheating.

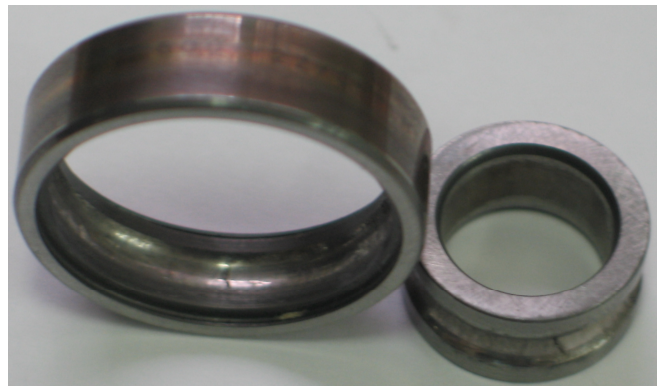

Fig. 12. Damage to the inner and outer ring

\section{The study of the durability of bearings 6001 with a spring of $100 \mathrm{~N}$}

Basing on the results of the previous experiment, it was decided to repeat it for the same two bearings with an additional axial tension introduced with the use of a cylindrical spring with the pressing force $100 \mathrm{~N}$. The scheme of this solution is shown in Fig. 13. The methodology of measurement was slightly changed. The record was done every hour so that it was possible to observe the early phase of damage.

The first approach to experiment with an axial load of $100 \mathrm{~N}$ failed and the device was completely damaged. As a result of bearings seizing, there was the rotor destroy. After the disassembly of the station the following conclusions were made:

- When we use the double-sided sealed bearings (6001-2Z), the introduced load causes rapid grease squeezing from the inside of the bearing, which leads to bearing seizure after 15 hours of work.

- Therefore, it is necessary to change the way of the lubrication of bearings so as to prevent their seizure.

In the experiment conducted again there were changed the conditions of bearings lubrication by introducing the lubricant in the space between bearings and changing applied bearings into one 
side sealed ones $(6001-Z)$. This solution worked perfectly, despite the increased operating temperature in relation to the original solution, the device did not show any signs of damage to the bearings up to 230th hour when the experiment was stopped. After demounting the stand the bearings showed no visible signs of wear.

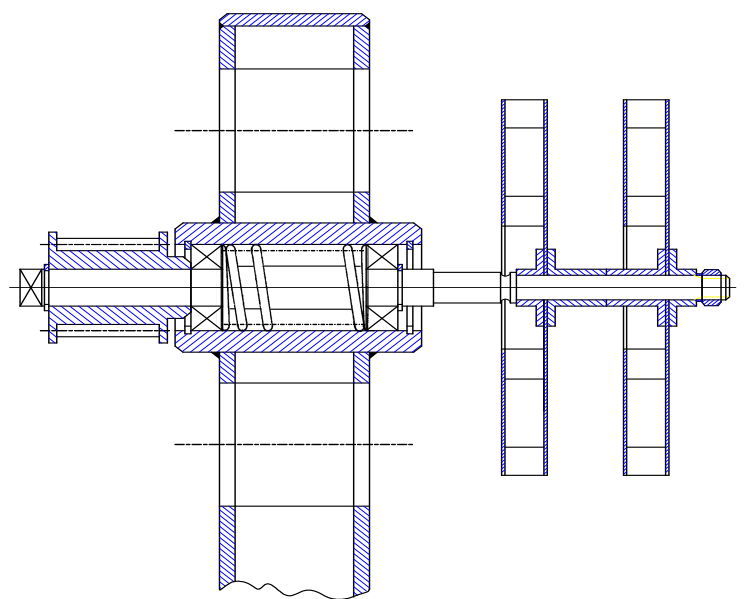

Fig. 13. Bearing scheme with a spring $100 \mathrm{~N}$

\section{Conclusions}

The experiment with an axial load of $100 \mathrm{~N}$, which was aimed to erase the clearances occurring in the bearing, allowed to draw the following conclusions:

- The introduction of additional axial force leads to stabilization of operation with decreasing the level of vibrations, but the temperature of work increases and it causes leakage of lubricant.

- Therefore, it is necessary to change the way of lubrication of bearings so as to prevent squeezing the grease between interacting surfaces.

- To reduce the influence of temperature on the conditions of bearings lubrication it is necessary to ensure the excess of lubricant.

Comparison of the stability of both structures is shown in Fig. 14 on the example of the course of RMS ratio.

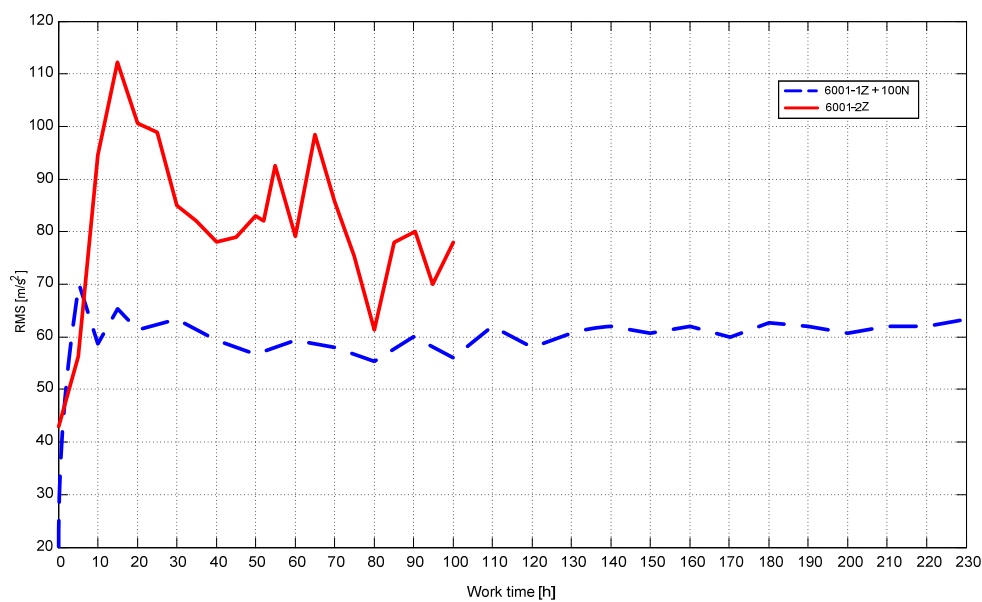

Fig. 14. Comparison of durability of applied constructional solutions.

To confirm the results and conclusions from both experiments there was performed an 
additional experiment for a changed constructional solution, with proper lubrication and without it. In the experiment, the emphasis was put on the first 20 hours of operation. The record of vibrational signal was performed every hour while performing a visual inspection of the system under study. The result of the experiment is shown in Fig. 15.

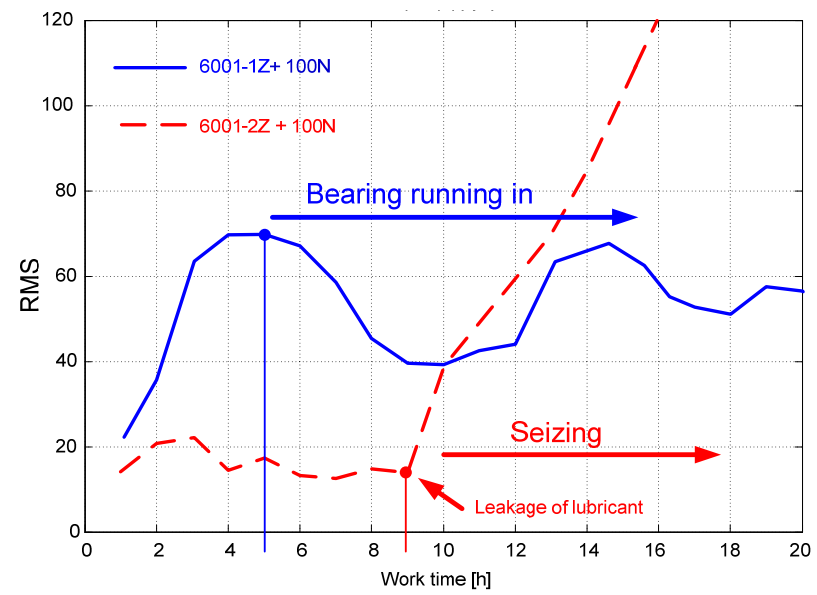

Fig. 15. The result of comparison of a 20 -hour operation of examined solutions of lubrication

The example graph clearly shows an increase in the general level of vibrations in the system, which uses an additional amount of lubricant. However, despite the increase in the general level of bearing vibration, it works stable, does not overheat and undergo accelerated degradation. Solution with factory default lubrication works well, in a short time of operation, when the amount of squeezed grease from the bearing does not exceed approx. $90 \%$ of its original volume. In the same period, the bearing with the excess of lubricant is a subject to the process of running in and the level of vibrations is reduced and stabilized. After 10 hours of work the seizing of the bearing without a proper lubrication causes (almost linear) rapid increase in the level of vibrations. The experiment was stopped before the assumed time (after 16 hours) to avoid seizing the bearing and destroying the station. Despite this, it occurred that the shaft journal where the bearing was placed was destroyed.

On the basis of the research, the following final conclusions may be drawn:

- Solution with an introduced additional axial load is successful because it minimizes clearances in the bearings, and thus leads to a significant increase in the durability of the device.

- At the same time it is necessary to ensure proper lubrication of bearings by introducing excess lubricant, otherwise accelerated squeezing the grease from new bearings causes premature seizure.

\section{References}

[1] Stanik Z. Typical failures in the damaged rolling elements made of different materials in the most important vehicle units. Archives of Metallurgy and Materials, Vol. 59, Issue 4, 2014, p. 1467-1473.

[2] Katunin A., Szrejber Z. Wear characterization of polymeric roller bearings during normal operation conditions and overloading. Scientific Problems of Machines Operation and Maintenance, Vol. 47, Issue 1, 2012, p. 39-49.

[3] Singh Sarabjeet, Koepke Uwe G., Howard Carl Q., et al. Analyses of contact forces and vibration response for a defective rolling element bearing using an explicit dynamics finite element model. Journal of Sound and Vibration, Vol. 333, Issue 21, 2014, p. 5356-5377.

[4] Petersen Dick, Howard Carl, Sawalhi Nader, et al. Analysis of bearing stiffness variations, contact forces and vibrations in radially loaded double row rolling element bearings with raceway defects. Mechanical Systems and Signal Processing, Vols. 50-51, 2015, p. 139-160. 
[5] Petersen Dick, Howard Carl, Prime Zebb Varying stiffness and load distributions in defective ball bearings: analytical formulation and application to defect size estimation. Journal of Sound and Vibration, Vol. 337, 2015, p. 284-300.

[6] Ahmadi Alireza Moazen, Petersen Dick Howard Carl A nonlinear dynamic vibration model of defective bearings - the importance of modelling the finite size of rolling elements. Mechanical Systems and Signal Processing, Vols. 52-53, 2015, p. 309-326.

[7] Pellegri M., Vacca A. CFD-radial motion coupled model for the evaluation of the features of journal bearings in external gear machines. Proceedings of the ASME/Bath Symposium on Fluid Power and Motion Control, 2015, p. V001T01A025.

[8] Singh S., Köpke U., Howard C., Petersen D. Analyses of contact forces and vibration response for a defective rolling element bearing using an explicit dynamics finite element model. Journal of Sound and Vibration, Vol. 333, Issue 21, 2014, p. 5356-5377.

[9] Singh S., Köpke U., Howard C., Petersen D., Rennison D. Impact generating mechanisms in damaged rolling element bearings. Proceedings of Acoustics, Australian Acoustical Society, Australia, 2013.

[10] Petersen D., Howard C., Sawalhi N., Ahmadi A. M., Singh S. Analysis of bearing stiffness variations, contact forces and vibrations in radially loaded double row rolling element bearings with raceway defects. Mechanical Systems and Signal Processing, Vols. 50-51, 2015, p. 139-160.

[11] Cooper Jonathan, Evans Tom, Petersen Dick Method for assessing tonality at residences near wind farms. International Journal of Aeroacoustics, Vol. 14, Issues 5-6, 2015, p. 903-908.

[12] Randall R. B., Antoni J. Rolling element bearing diagnostics - a tutorial. Mechanical Systems and Signal Processing, Vol. 25, Issue 2, 2011, p. 485-520.

[13] Dziurdz J. Modelling of the toothed gear operations with the application of the analysis of the gear sliding mesh velocity changes. Mechatronic Systems, Mechanics and Materials, Solid State Phenomena, Vol. 180, 2012, p. 200-206.

[14] Xi F., Sun Q., Krishnappa G. Bearing diagnostics based on pattern recognition of statistical parameters. 5th International Congress on Sound and Vibration, Adelaide, Australia, Vol. 2, 1997, p. 985-992.

[15] Sun Q., Xi J., Chen P., Krishnappa G. Bearing condition monitoring through pattern recognition analysis. 6th International Congress on Sound and Vibration, Copenhagen, Denmark, 1999, p. 3009-3016.

[16] Deuszkiewicz P., Radkowski S. On-line condition monitoring of a power transmission unit of a rail vehicle. Mechanical Systems and Signal Processing, Vol. 17, Issue 6, 2003, p. 1321-1334.

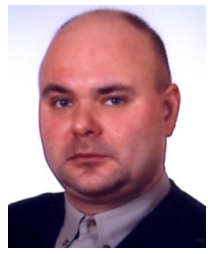

Piotr Deuszkiewicz is employed as an Assistant Professor at the Warsaw University of Technology, Faculty of Automotive and Construction Machinery Engineering, Institute of Machine Design Fundamentals, Department of Fundamentals of Machine Design and Operation. Currently he is headmaster of Vibroacoustic Laboratory. He received Ph.D. (2012 Warsaw University of Technology, Faculty of Automotive and Construction Machinery Engineering). His research interests are: vibration phenomena, machinery diagnostic, signal processing, dynamics of drive systems, mechanics of modern composite materials. He is member of Polish Societies of Technical Diagnostics. 